\title{
L'esperit empresarial des de la perspectiva del gènere
}

\author{
Ignasi Brunet
}

Universitat Rovira i Virgili

ignasi.brunet@urv.cat

Rebut: $20-04-2010$

Acceptat: 28-03-2011

\section{Resum}

Aquest article sintetitza els discursos produïts per dones empresàries sobre la influència de la variable gènere en la creació i la gestió d'empreses. Influència que actua en dues direccions: d'una banda, en l'assumpció del rol de "superdona», per part de dones que mantenen una intensa proximitat afectiva amb la família i que assumeixen una compatibilitat total entre l'àmbit reproductiu i l'àmbit productiu (en aquest cas, l'empresa, com a instrument d'autonomia per satisfer aquesta compatibilitat); de l'altra, en l'assumpció del rol de «superhome», és a dir, en la imitació del gènere socialment assignat als homes, que es tradueix en la supeditació de tot allò relacionat amb l'àmbit domèstic respecte a l'objectiu d'èxit professional.

Paraules clau: gènere; creació d'empreses; conciliació laboral; empresàries.

\section{Abstract. Entrepreneurship from a gender perspective}

This paper synthesises the discourse produced by female employers regarding the influence of gender in the creation and management of business; that is, the influence of the gender variable in two dimensions. First, it has an effect on the assumption of the "superwoman" role by women who have intense, close and affectionate relationships with their families and who assume full compatibility between the reproductive sphere and the productive sphere. In this case, the enterprise is an instrument of autonomy which satisfies this compatibility. Second, the gender variable also influences their assumption of the "superman" role whereby they imitate the social role assigned to men, and which implies the subordination of domestic issues to the goal of professional success.

Key words: gender; enterpreneurship; laboral conciliation; businesswomen.

\section{Sumari}

\section{Introducció 4. Conclusions}

2. Marc i estratègia de la investigació $\quad$ 5. Bibliografia

3. Anàlisis de la informació 


\section{Introducció}

El discurs relatiu a l'esperit emprenedor com a motor de les economies modernes està incorporat en la política empresarial comunitària quan insisteix en l'important paper que haurien d'ocupar les empreses per fer d'Europa «l'economia més competitiva i dinàmica del món». D’acord amb aquesta política, el llibre verd de la Comissió Europea (2003) estableix les cinc àrees estratègiques prioritàries següents:

1) Promoure l'esperit emprenedor entre els joves.

2) Atenuar l'estigma del fracàs empresarial.

3) Donar suport a les dones i a les minories ètniques en aquest àmbit.

4) Reduir la complexitat administrativa de la flexibilitat empresarial.

5) Facilitar els traspassos d'empreses.

Basant-nos en la tercera àrea, en la present recerca, ens hem proposat contextualitzar aquest discurs i les pràctiques efectives de creació d'empreses des de la perspectiva de gènere. Concretament, aquesta investigació es va plantejar pels motius següents:

1) En primer lloc, la revisió de la literatura mostra com els efectes de la divisió sexual del treball sobre la situació professional de les dones i, més concretament, sobre la creació d'empreses, constitueix un camp d'estudi amb certa trajectòria internacional (Carter, 2000; Shaw et al., 2001; Caputo i Dolinsky, 1998; Connelly, 1992; Williams, 2004; Marlow, 2002; Bodey, 1999), no obstant això, detectem una llacuna acadèmica a Espanya i a Catalunya.

2) En segon lloc, vam considerar pertinent plantejar aquesta investigació per, a partir del Consell Europeu d'Amsterdam de 1997, promoure l'esperit empresarial i la innovació. Constitueix un dels objectius principals de l'estratègia europea per a l'ocupació, tant a escala nacional com de la Unió Europea en conjunt. A més a més, l'acadèmia també s'ha interessat per la creació d'empreses com a camps d'investigació i de docència (Veciana, 1999; Cuervo, 2005; Urbano, 2006; Lundström i Stivenson, 2001, 2002).

\section{Marc teòric i estratègia de la investigació}

A nivell internacional, existeix un creixent nombre d'investigacions relatives a les dones emprenedores que s'evidencia en l'augment de forums d'experts internacionals (vegi's, per exemple, OCDE, 2001). A més, recentment, les investigacions tendeixen a donar rellevància a la variable gènere per explicar la creació i l'èxit de les empreses (Kantor, 2002). A partir d'aquest fet, ha sorgit una literatura entorn del denominat «despertar femení» i/o «emprendre femení», aplicat a la creació i gestió d'empreses. Literatura que emfatitza la complementarietat d'home i dona, situant l'accent en la diversitat de gènere abans que en la desigualtat de gènere (Chinchilla i León, 2003, 2004; Pérez i Chinchilla, 
1995; Mercadé, 1998). Mantenir els perfils de gènere com a antagònics suposa, des d'aquest enfocament, fer una anàlisi equivocada, ja que les empreses necessiten no tant rebutjar el punt de vista masculí, com incorporar el que les dones puguin aportar al món empresarial per plantar cara a les noves situacions que hi tenen lloc. Aquesta literatura ha presentat les dones com a persones amb valors positius que poden aportar al desenvolupament econòmic $\mathrm{i}$ al progrés social. L'increment paulatí de dones que ocupen llocs directius adquireix un alt valor simbòlic que contribueix a revaloritzar el que és «femení» i a modificar les creences estereotipades respecte a la falta d'aptituds o d'actituds directives de les dones. L'argument empresarial bàsic que utilitza aquesta literatura per sostenir la diversitat és que aquest criteri augmenta els beneficis econòmics, atès que afavoreix que les treballadores estiguin més motivades i més ben preparades. I els augmenta perquè les dones no han de ser pas ni més ni menys ambicioses que els seus companys homes ni més ni menys optimitzadores, ni més ni menys predisposades a visualitzar oportunitats, ni més ni menys emprenedores que els seus companys emprenedors.

D'altra banda, aquesta literatura sosté que dones i homes posseeixen experiències passades i maneres de pensar diferenciades. Aquestes formes diferenciades de gènere no poden ser considerades menys vàlides les unes que les altres (Fisher et al., 1993) pel que respecta a l'acumulació de capital. A més, s'identifica la disponibilitat d'ingressos monetaris amb la situació en el mercat laboral. Aquesta equiparació s'estableix tant a nivell individual com en termes de cada llar, i es basa en la consideració que les llars són unitats harmonioses on tots els recursos es comparteixen equitativament. Aquesta visió de la llar com una unitat harmoniosa sol anar unida a la consideració que tots els membres que en formen part i que no tenen cap feina assalariada depenen dels ingressos de qui sí que està en el mercat laboral, amb la qual cosa s'identifica una dependència última de l'ocupació de qui ostenta el paper de guanyador de diners. Quan el nexe s'estableix en termes individuals, s'està negant l'existència de xarxes socials que comparteixin recursos i que n'intercanviïn, com també que permetin minimitzar la necessitat de cada persona d'obtenir ingressos propis, tant si es tracta d'aquestes xarxes, les llars o altres. És a dir, o bé es construeix un discurs individualista, on la responsabilitat d'obtenir ingressos recau sobre cada persona (salari directe o diferit), o bé s'opta per un discurs on les llars apareguin com a unitats harmonioses (Pérez Orozco, 2007: 198).

Desenvolupant aquest argument, Carter i Williams (2003) parteixen de la hipòtesi que l'èxit de les iniciatives empresarials no ha de diferir entre homes $i$ dones. El que en diferiria serien les estratègies que es desenvolupen en funció de les diferències de gènere. No obstant això, la contrastació afirmativa d'aquesta hipòtesi no s'arriba a produir, ja que, seguint Carter i Williams, l'èxit empresarial s'observa no en el procés, sinó pels resultats que reflecteixen normes masculines. Així, malgrat que les característiques femenines guanyen en reconeixement i valor, a l'èxit en els negocis se segueix aplicant el patró masculí (Bradley, 1999). D'aquesta manera, aquesta literatura no aconsegueix explicar la persistència dels valors patriarcals i els estàndards masculins que 
impedeixen el reconeixement de les diferents visions d'èxit segons el gènere, i és que aquest enfocament ignora que l'estatus d'empresàries no implica que les obligacions familiars i les tasques relacionades amb la llar i la família es reparteixin de manera més equitativa. Així mateix, en aquesta literatura, els mercats, les empreses i la seva lògica d'acumulació mantenen la seva centralitat. Mercats, empreses que no assumeixen cap responsabilitat en la sostenibilitat de la vida, perquè satisfer necessitats no és el seu motor d'actuació, sinó un efecte secundari que pot aparèixer o no mitjançant el funcionament o que, fins i tot, pot dificultar-se o impedir-se. La prioritat social concedida als mercats suposa que la societat en conjunt no fa seva la responsabilitat de garantir la sostenibilitat de la vida. En paraules de Devi (2000: 28): «no és possible una societat que valori la cura amb una estructura de producció que produeix a gran escala, amb la urgència per l'increment constant de la productivitat, guiada, sobretot, pel motor del benefici».

D'altra banda, existeix una falta d'integració generalitzada entre aquest camp d'estudi i els avenços acadèmics obtinguts en relació amb la participació de la dona en el mercat de treball (Greer i Green, 2003). Fins i tot, quan la investigació sobre les empreses ha posat l'èmfasi en la família, com és el cas de l'estudi de l'empresa familiar, l'anàlisi majoritàriament s'interessa pels beneficis econòmics, el problema de la successió o l'estructura de la propietat i del govern de l'empresa, i deixa al marge l'examen de com s'organitzen les persones en aquestes famílies i com es reparteixen el consum, la feina i l'oci (Sacristán, 2002; Gallo, 1997). A més a més, a Espanya i a Catalunya, la qüestió del paper del gènere en la creació d'empreses és un camp poc desenvolupat. S'hi ha incorporat la variable gènere en relació amb preocupacions més específiques, com ara els negocis ètnics (Solé i Parella, 2005; Sáiz, 2003; Oso i Ribas, 2004) o la creació d'empreses en espai rural (Cánoves, 1994; Cánoves i Garcia Ramon, 1995; Garcia Ramon i Baylina, 2000; Sampedro, 1996; Cánoves i Villarino 2000a, 2000b). Paradoxalment, no disposem de cap investigació que prengui com a unitat d'anàlisi la dona autòctona i urbana respecte a aquest objecte d'estudi. No obstant això, vam tenir una important tradició en la investigació sobre la relació entre treball productiu i treball reproductiu, sota el tòpic de conciliació entre vida laboral i familiar. Precisament, la qüestió de la conciliació esdevé un punt clau en el moment de comprendre les relacions entre gènere i creació d'empreses. Es tracta, per tant, de sotmetre a anàlisi el bagatge teòric acumulat a unes altres situacions laborals distintes de l'ocupació per compte aliè, i és que, malgrat que la investigació centrada en la creació d'empreses disposa d'un conjunt rellevant d'investigadors, aquests s'han centrat, genèricament, en la creació, en la rotació, en la innovació o en el paper de les institucions en la promoció de l'esperit emprenedor i la creació d'empreses (Segarra, 2002; Díaz, 2002; Urbano i Veciana, 2001; Veciana, 1985, 1988, 1999, 2005, entre altres). Per tot això, ens interessa contrastar si, en el cas de les emprenedores, l'opció per a l'autoocupació rau en la suposada flexibilitat que aquesta reporta i que permetria establir una conciliació de vida laboral i familiar millor o bé si rau en estratègies orientades a l'alliberament de tasques reproductives no reconegudes 
socialment. Alliberament d'acord amb els «ideals d'èxit» masculí, és a dir, es tracta d'una estratègia orientada a assimilar els estereotips masculins en relació amb l'activitat productiva i reproductiva.

En el plantejament metodològic d'aquesta investigació, el treball de camp i la recollida d'informació s'han efectuat en dues etapes. En un primer moment, s'ha identificat la situació de les dones emprenedores per conèixer quantes són i quines en són les característiques sociodemogràfiques. Les fonts d'informació per cobrir aquesta etapa han estat dades secundàries ja existents, concretament, les bases de dades de les associacions de dones empresàries. L'anàlisi quantitativa d'aquesta informació, tant en relació amb les característiques de les dones com amb les característiques de les empreses creades per elles, ens ha permès centrar la recerca en els emprenedors i les emprenedores per oportunitat (Brunet i Alarcón, 2005), atès l'impacte de l'activitat d'aquestes persones emprenedores sobre el creixement econòmic; impacte que, a causa del seu alt nivell de formació, no es manifesta de la mateixa manera en països amb nivell diferent de desenvolupament (Acs et al., 2005). L'activitat dels emprenedors i les emprenedores d'oportunitat té un efecte positiu, segons l'evidència empírica disponible a escala internacional (Audretsch i Thurik, 2002), sobre el creixement del PIB en els països amb un nivell alt d'ingressos, però no tant en països més pobres, fet que es pot explicar pels baixos nivells de capital humà que caracteritzarien les persones emprenedores en països en vies de desenvolupament. Així, en les economies més avançades i pròsperes, hi apareixen emprenedors amb un alt nivell de formació, impulsats per la percepció en el mercat d'oportunitats de negoci que no han estat explotades prèviament. Per tant, quan es pretén analitzar la repercussió dels emprenedors sobre el creixement econòmic, no n'hi ha prou de prendre en consideració exclusivament el nombre total de nous naixements d'empreses, sinó les característiques que tenen i les condicions socioeconòmiques dels països o les regions on estan ubicades (Guzmán i Romero, 2006). Per tot això, s'ha cregut convenient enfocar l'anàlisi a un perfil d'emprenedors i emprenedores que són persones treballadores del coneixement, és a dir, amb un elevat capital formatiu, pertanyents a classes professionals, amb edats compreses entre els trenta $\mathrm{i}$ els quaranta-cinc anys, que provenen de famílies també amb estudis superiors i vinculades a sectors de la «nova economia». S'ha cregut convenient enfocar l'anàlisi en aquest col-lectiu perquè s'adequa millor al que la retòrica econòmica entén per emprenedoria i, concretament, emprenedoria per oportunitat. Aquest perfil de persones emprenedores es va contrastar amb les bases de dades de les associacions de dones empresàries a Catalunya.

En una segona etapa, el treball de camp es va dirigir a recollir dades primàries a partir d'una metodologia qualitativa (entrevistes i grups de discussió), en ser útil per analitzar els fenòmens culturals i ideològics, és a dir, les idees, les opinions, les actituds, les motivacions, les representacions i les imatges de la gent sobre tot tipus de qüestions o aspectes de la vida social. A pesar que l'objecte central d'aquesta investigació són les dones, es va considerar convenient recollir informació tant dels discursos que construeixen aquestes com dels discursos que construeixen homes emprenedors que presenten les matei- 
xes característiques sociològiques. També es van tenir en compte els cònjuges d'empresàries i empresaris, per aprofundir sobre la distribució del treball productiu i el treball reproductiu prenent com a unitat d'anàlisi la família. D'altra banda, es va procedir també a realitzar entrevistes a associacions de dones empresàries.

La informació obtinguda dels discursos de les dones i dels homes empresaris és la que sintetitzem en aquest article ${ }^{1}$.

\section{Anàlisi de la informació}

\subsection{El context de la creació d'empreses}

La nostra recerca s'ha emmarcat en un context de recessió econòmica que està afectant l'ocupació masculina en un nivell més elevat. Aquesta situació fa que, l'any 2008, les diferències en les taxes d'ocupació masculina i femenina s'hagin reduït més d'un 30\% si ho comparem amb els principis de la dècada, mentre que les taxes d'atur femení, que a principis de la dècada pràcticament doblaven les masculines, ara són molt més pròximes i, a Catalunya, inusualment equilibrades.

1. El conjunt de treball de camp de la investigació, centrat a Catalunya, és de 22 entrevistes en profunditat: $7 \mathrm{a}$ responsables d'associacions d'empresàries, $10 \mathrm{a}$ emprenedores i 5 a emprenedors. També s'han organitzat 5 grups de discussió: 1 amb dones empresàries, $1 \mathrm{amb}$ homes empresaris, 1 de mixt, $1 \mathrm{amb}$ cònjuges $\mathrm{o}$ parelles d'empresaris i empresàries i $1 \mathrm{amb}$ tècnics de l'Administració pública (especialment responsables de vivers d'empresa), amb una participació de 30 individus: 18 dones i 12 homes.

La codificació de les citacions és la següent:

- Entrevistes a emprenedores. EDE1: fisioterapeuta i osteòpata. EDE2: dissenyadora gràfica. EDE3: advocada. EDE4: economista. EDE5: il.lustradora de literatura infantil i juvenil. EDE6: dissenyadora gràfica. EDE7: dissenyadora de programari. EDE8: biòloga. EDE9: antropòloga. EDE10: psicòloga.

- Grups de discussió. GDD1 (grup de discussió de dones emprenedores). 6 participants: $a$ ) treballadora per compte propi, productora gràfica; $b$ ) traductora; $c$ ) dissenyadora gràfica; $d$ ) formadora; $e$ ) enginyera; $f$ traductora. GDM2 (grup de discussió mixt). 8 participants: $a$ ) home, estudi d'arquitectura; $b$ ) home, consultoria política; $c$ ) home, estudi d'arquitectura; $d$ ) dona, estudis i projectes socials; $e$ ) dona, estudis geogràfics; $f$ ) dona, serveis informàtics; $g$ ) dona, formació contínua per a empreses; h) home, disseny gràfic i industrial. GDT3 (grup de discussió de tècnics). 5 participants: $a$ ) tècnica, Barcelona Activa; $b$ ) tècnica, Ajuntament de Sant Joan Despí; $c$ ) tècnica, Ajuntament de Sant Adrià del Besòs; $d$ ) tècnica, Pla de la Dona; $e$ ) tècnica, Ajuntament de Cornellà de Llobregat. GDC4 (grup de discussió de cònjuges d'empresaris). 5 participants: a) cònjuge d'empresari de construcció; $b$ ) cònjuge d'empresari de consultoria i producció química; $c$ ) cònjuge d'advocat amb bufet propi; $d$ ) cònjuge d'empresària en consultoria social; $e$ ) cònjuge d'empresària en contractació de personal. GDH5 (grup de discussió d'homes empresaris). 6 participants: a) empresari de construcció; $b$ ) empresari d'instal.lacions elèctriques i informàtiques; c) guionista; $d$ ) advocat amb bufet propi; e) empresari de comercialització de productes per a laboratori; $f$ ) empresari de producció química. 
Taxes d'ocupació i atur (16 a 64 anys) per sexe. Mitjanes anuals. Catalunya i Estat espanyol. Anys 2001-2006-2007-2008

\begin{tabular}{|c|c|c|c|c|c|c|}
\hline & & & 2001 & 2006 & 2007 & 2008 \\
\hline \multirow{4}{*}{ Ocupació } & \multirow{2}{*}{ Catalunya } & Homes & 78,6 & 81,3 & 81,3 & 78,5 \\
\hline & & Dones & 52,7 & 61,3 & 62,3 & 63 \\
\hline & \multirow{2}{*}{ Espanya } & Homes & 73,5 & 77,3 & 77,4 & 74,6 \\
\hline & & Dones & 43,8 & 54,0 & 55,5 & 55,8 \\
\hline \multirow{4}{*}{ Atur } & \multirow{2}{*}{ Catalunya } & Homes & 6,5 & 5,3 & 5,6 & 9,1 \\
\hline & & Dones & 11,7 & 8,4 & 7,9 & 9 \\
\hline & \multirow{2}{*}{ Espanya } & Homes & 7,6 & 6,4 & 6,4 & 10,1 \\
\hline & & Dones & 15,3 & 11,6 & 10,9 & 13,1 \\
\hline
\end{tabular}

Font: EPA.

En aquest context de bloqueig del mercat laboral, l'ocupació per compte propi ha augmentat entre les dones: a Catalunya, de 2001 a 2008 ha augmentat en 32.000 dones, amb una taxa de creixement del $21,2 \%$ (superior a la masculina, del 14,3\%). Ara bé, aquest creixement en dades absolutes no es reflecteix en el percentatge que aquestes dones representen sobre el total de dones ocupades, atès, precisament, que actualment (novembre de 2009) la recessió econòmica encara no ha afectat l'ocupació femenina de la mateixa forma que ho està fent amb la masculina, i el percentatge de dones ocupades l'any 2008 encara és molt superior al que hi havia a principis de la dècada. Així, el 2008, un de cada cinc homes ocupats treballava per compte propi, entre 7 i 8 punts per sobre del comportament femení, una situació pràcticament idèntica a la de l'any 2001 a Catalunya.

Per tant, l'evolució de les dades d'ocupació, atur i ocupació per compte propi tendeixen a un lent però constant equilibri per sexes, encara que en pràcticament tots els indicadors el desequilibri encara és profund.

Percentatge de població ocupada per compte propi en relació amb el total de població ocupada, per sexe. Mitjanes anuals. Catalunya i Estat espanyol. Anys 2001-20062007-2008

\begin{tabular}{lllrrrr}
\hline & & & 2001 & 2006 & 2007 & 2008 \\
\hline \multirow{4}{*}{ Ocupació } & \multirow{3}{*}{ Catalunya } & Homes & 20,6 & 20,5 & 20,0 & 20,4 \\
& & Dones & 13,4 & 12,8 & 11,6 & 12,0 \\
& \multirow{2}{*}{ Espanya } & Homes & 21,8 & 20,6 & 20,5 & 20,8 \\
& & Dones & 16,2 & 13,8 & 13,5 & 13,3 \\
\hline
\end{tabular}

Font: EPA.

Unes altres dades apunten en una direcció semblant. L'informe Global Entrepreneurship Monitor, de 2008 (Guallarte, 2009), apunta, tant per al cas català com per a l'espanyol, cap a una equiparació de la taxa d'activitat 
emprenedora femenina, la qual reflecteix el percentatge de població de divuit a seixanta-quatre anys involucrada en empreses de creació recent (menys de tres mesos d'antiguitat) i empreses noves (de tres a quaranta-dos mesos). Aquesta equiparació es deu tant a un augment de l'activitat emprenedora en les dones com a una reducció (sobretot a Catalunya) de l'activitat emprenedora en els homes, fet que apunta a una resistència més gran de l'activitat emprenedora femenina en contextos d'estancament o recessió econòmica. L'any 2008 ja hi havia 83 dones vinculades d'alguna manera amb l'activitat emprenedora per cada 100 homes (quan, per exemple, l'any 2003 eren 37).

Taxa d'activitat emprenedora (TEA) segons sexe. Catalunya, Espanya, Unió Europea. 2003-2005-2008

\begin{tabular}{lcccccccc}
\hline & \multicolumn{2}{c}{2003} & & \multicolumn{2}{c}{2005} & & \multicolumn{2}{c}{2008} \\
\cline { 2 - 3 } \cline { 8 - 9 } & Homes & Dones & & Homes & Dones & & Homes & Dones \\
\hline Catalunya & 11,5 & 4,0 & & 8,9 & 4,9 & & 7,9 & 6,6 \\
Espanya & 9,5 & 4,0 & & 7,2 & 4,2 & & 8,1 & 6 \\
Unió Europea & 7,9 & 3,3 & & 7,4 & 3,6 & & 8 & 4 \\
\hline
\end{tabular}

Font: Guallarte et al. (2006) i Guallarte (2009).

$\mathrm{Al}$ mateix informe, s'hi detecta una elevada homogeneïtat en les característiques de la iniciativa emprenedora entre homes i dones, especialment quan aquesta ja s'ha iniciat (a excepció del temps que es pot dedicar a l'empresa, que segueix sent un llast per a les dones). Per exemple, entre els que han començat una activitat empresarial, no hi ha diferències per raó de gènere quant a factors psicosocials (qüestions relatives, per exemple, a la capacitat de detectar oportunitats, de por al fracàs o d'habilitats per al lideratge). La vinculació sectorial tampoc no presenta diferències, i només apareix una participació masculina més baixa en determinats tipus de negocis. El tipus d'activitat emprenedora és similar per tots dos sexes: en vuit de cada deu casos es deu a la detecció d'una oportunitat de negoci, mentre que l'emprenedoria per motius de necessitat és residual. Les poques diferències existirien en: $a$ ) un augment de l'edat mitjana femenina entre les emprenedores en fase inicial; b) una concentració femenina més gran, en aquesta fase inicial, en els trams de renda més baixos; una motivació femenina més elevada a mantenir els ingressos, mentre que els homes tendeixen a preferir els guanys en independència, i $c$ ) més diversificació dels perfils de dones que han abandonat l'activitat empresarial respecte als homes (concentrats en individus d'edat avançada i estudis primaris).

\subsection{Factors condicionants de la creació d'empreses}

Per donar suport i fomentar empíricament l'emprenedoria, existeix, en els últims anys, la convicció que és imprescindible crear un entorn institucional determinat. De fet, és extensa i àmplia la literatura que considera els factors 
institucionals de l'entorn com a condicionants de la creació de noves empreses. En harmonia amb aquesta literatura, s'han establert, en primer lloc, polítiques governamentals, tant en l'àmbit general de les normes i les legislacions que regulen l'entorn de l'activitat empresarial, com en l'àmbit més específic dels incentius fiscals i dels tràmits administratius en la creació d'una empresa. En segon lloc, s'han elaborat mesures de suport globals a les Pimes i a la creació d'una empresa, i, en tercer lloc, mesures específiques de suport als nous empresaris: serveis i programes no econòmics d'assistència (informació, assessorament, formació, vivers d'empreses, etc.) i ajudes econòmiques (préstecs, subvencions, capital de risc, avals, etc.). Tots aquests factors institucionals que aborden els factors formals relacionats amb el procés de creació d'empreses plantegen «interrogants» per part dels nostres informants, en el sentit que no constitueixen variables que hagin condicionat la constitució i el procés de consolidació de l'empresa en la qual estan enrolats. «Interrogants» que sorgeixen de la identificació que efectuen les institucions formals entre creació d'empreses i gestió d'empreses, en el sentit de posar, com a requisit per obtenir una ajuda, el fet de tenir o fer "un pla d'empresa», un "pla de viabilitat de l'empresa». La informació recollida no avala aquesta identificació, atès que, per als nostres informants, que procedeixen del món universitari i tots són treballadors i treballadores del coneixement, el prioritari és disposar d'autonomia "personal» (EDE2), estar «a gust» (EDE3), estar «feliç» (EDE6), i no «aquest pla d'empresa del qual es parla tant» (EDE7). Això evidencia i explica els interrogants que tenen sobre els recursos institucionals per emprendre, atès que es perceben com a treballadors i no com a gestors. Ser gestors, per a ells, és "com caure en un parany» (EDE8) i entrar en una dinàmica "que tens una estructura que cal mantenir, que t'exigeix uns peatges per poder mantenir aquesta estructura» (EDE4). Una de les causes d'aquests «interrogants» és que els nostres informants no tenen el concepte d'empreses ni d'empresarialitat com el que posseeixen les institucions formals, en el sentit d'un conjunt de comportaments planificats que influeixen en la configuració i la millora d'un tipus determinat d'estructura productiva i empresarial $i$, per tant, en el creixement $i$ el desenvolupament d'una economia. Pel que respecta als factors institucionals informals que afecten el procés de creació de l'empresa, les persones informants destaquen, prioritàriament, ser autosuficients —aportació personal (estalvis, capitalització de l'atur) —, atès que la percepció general és que «a nivell d'ajudes en general per constituir una empresa, a Espanya la cosa està horrorosament malament, per ser dona, fatal. I, a Catalunya, no té noms» (EDE8). En segon lloc, si no s'és autosuficient: crèdits bancaris i préstecs o ajudes de l'entorn social (amics i familiars). En tercer lloc, referent als factors informals, es fa bastant èmfasi en l'experiència professional prèvia, la formació acadèmica $i$, sobretot, en el contacte amb clients, atès que és tan important «l'experiència professional, a part de la formació acadèmica» (EDE8), com «el capital social» (GDH5). Els factors informals duen al diagnòstic següent explicitat pels nostres informants: la gestió ineficient de les polítiques de suport per a la creació i el desenvolupament d'una empresa, atès que «hi ha tants tràmits per demanar 
coses, que no tinc temps» (EDE8). Les polítiques públiques i els mecanismes existents de suport són valorats com a no adequades. No hi ha una adequació dels serveis a la creació d'empreses, a les necessitats específiques dels nous empresaris i empresàries. En qualsevol cas, això s'explica perquè els nostres informants identifiquen, en primer lloc, empresarialitat o funció empresarial amb la funció capitalista, que és aquella que ocupa l'empresari quan aporta capital a l'empresa perquè aquest pugui desenvolupar la seva activitat. Per aquest motiu, consideren molt important les «reserves de capital, inversions en actiu i xarxa de cobrament» (GDH5). L'empresari apareix com el capitalista, la funció empresarial i la funció del capital són identificades. En segon lloc, amb la funció impulsora i/o emprenedora, que és aquella l'acompliment de la qual implica l'assumpció d'una sèrie d'iniciatives perquè el negoci pugui començar a funcionar en el mercat.

El factor desencadenant de la funció impulsora no és la detecció d'una oportunitat de benefici, ni assumir una sèrie d'activitats de caràcter innovador, sinó Internet. Perceben que Internet i les noves tecnologies de la informació i la comunicació els ha canviat la vida laboral. Representa la condició de possibilitat d'autoocupar-se explotant la força dinàmica d'aquestes tecnologies, però en cap cas se'ns informa que la funció impulsora va ser la detecció d'unes oportunitats i l'escomesa d'accions necessàries per captar els beneficis. En tot cas, per a les persones informants, Internet no representa la possibilitat de fer molts diners. Òbviament, no s'assemblen gens a empreses gegants com Cisco, Dell, Google, eBay, Skype, Amazon o Yahoo. La funció impulsora no està en "quina empresa muntar» (EDE6), sinó, bàsicament, a "sentir-me autònoma» (EHE1, EDE9), és a dir, a «sentir-me realitzada. Quan treballes per a una altra persona, estàs limitat, $\mathrm{i}$ amb aquest projecte em trobo que puc fer i desfer. Treballo moltes hores, però vaig cap a casa contenta, que és l'important» (EDE4). El prioritari no és la idea d'empresa, tenir un "pla d'empresa», ser algú innovador. L'oportunitat s'associa amb ser professional, amb ser autònom, i això «per no tenir cap» (EDE5).

En tot cas, els components de la funció empresarial (detectar i captar les oportunitats de beneficis dels mercats, afrontar el risc, la incertesa i innovar) no els hem detectat en les persones informants, a part que resulten ser components altament ambigus, imprecisos i, en última instància, estèrils. Per a elles, el seu «projecte empresarial» és una forma de disposar d'autonomia personal $i$, per assolir-la, el mitjà va ser Internet. En definitiva, no s'associa empresarialitat a la «funció gerencial», que és aquella que ocupa l'empresari quan dirigeix, organitza, gestiona, planifica o contracta el funcionament de la seva empresa. Aquesta funció està plenament assumida per les tècniques i els responsables de serveis de suport a l'emprenedor o l'emprenedora, i que defineixen el seu treball com una feina «més de gestió d'un viver d'oficines i menys de gestió d'un viver d'empreses» (GDT3). Tècnics que igualen empresarialitat a tenir un pla d'empresa i que subratllen que la «major part de persones hi vénen per tenir un petit negoci, fer d'autònom». Quan se'ls planteja que demanar un crèdit bancari exigeix un pla d'empresa, un pla gerencial o un projecte d'empresa, 
ens comuniquen que funcionen sense haver fet aquest exercici previ, perquè «és com caure en un parany, diguem, acabes sent un gestor, però amb més treballadors, més facturació, etc.» (EDE7).

Temen la funció gerencial, perquè "perdo el control. Per a mi, seria entrar a diferenciar entre aquell que va a la recerca dels diners i li és igual si fa cargols com si ven serveis, del que li agrada la seva història i s'hi dedica» (GDM2). La qüestió que es ressalta sempre és el tema «aquest de treballar per viure o viure per treballar, encara que un faci el que li agrada, això és molt important plantejar-s'ho, eh! Com a home i com a dona, com a ésser humà» (EDE4, EHE5). A més a més, afirmen que volen consolidar-se, créixer, però no en "quantitat», sinó en "qualitat», és a dir, "consolidar un bon equip» (EDE1), «aconseguir la màxima satisfacció del client» (EDE4), «fidelitzar clients» (EDE10), «crear marca d'empresa» (EDE5), «bon ambient de treball perquè el personal estigui motivat» (EDE7), "experimentar a nivell vital — sortir, viatjar, etc. — per alimentar-se intel-lectualment» (EDE10), "participar en projectes interdisciplinaris» (EDE10), «bona entesa entre els socis» (EDE9), «acumular un capital que permeti gaudir de més autosuficiència" (EHE3), "prudència en les despeses $\mathrm{i}$ les inversions», «diversificar clients» (EHE2). Créixer no és sinònim de créixer físicament, de ser ric, sinó que és "poder seleccionar els clients» (EHE5) i tenir «el millor producte en el mercat» (EDE6).

Dèiem que les polítiques institucionals de suport i foment a l'empresarialitat no s'adequaven a les necessitats específiques de les persones informants. El problema rau a veure què s'entén per empresarialitat, per empresari i per emprenedor. Més específicament, el problema rau a associar l'empresarialitat exclusivament al comportament individual de l'home o de la dona empresari o emprenedor. De fet, quan es parla de les capacitats empresarials i/o emprenedores, aquestes es consideren des d'una perspectiva individual. Tot sembla indicar que empresaris i empreses actuen responent a factors individuals, de caràcter personal o particular de la persona empresària i de l'empresa. Això duu a buscar la ràtio d'ocupats per compte propi sobre la població ocupada, la ràtio sobre la capacitat innovadora, la ràtio d'empreses que moren o que neixen cada any, i així successivament. Ara bé, el que emergeix de la informació recollida és el caràcter col-lectiu de l'empresarialitat, en el sentit que cal tenir menys en compte el paper de la persona empresària o emprenedora (nivell individual), i més el teixit empresarial, és a dir, el conjunt d'agents que ocupen la funció empresarial, i són empresaris aquells agents que ocupen algun component de la funció empresarial associada amb el teixit empresarial. Per tant, la funció empresarial és el resultat d'un comportament col-lectiu determinat, que pot ocupar-se individualment per una sola persona física o de manera corporativa per un conjunt d'agents, com ocorre en les grans empreses. En la categoria d'empresaris o emprenedors corporatius, se situarien la figura productiva dels directius, els tècnics, els quadres, mentre que, en la categoria d'empresaris o emprenedors, hi entrarien les persones informants. D'altra banda, la consideració del comportament de les empreses és fonamental si es vol explicar o esbrinar amb més precisió què s'entén actualment per empresarialitat, i és que «ara sóc 
autònoma actualment, però perquè en un dels contractes m'exigien que el contracte havia de ser com a autònoma, o sigui que jo realment de satisfeta no n'estava, no ho hagués fet» (EDE1).

Referent al contingut de la funció empresarial, es destaquen les perspectives que la identifiquen amb la innovació. Però, per la nostra banda, el que s'observa és el caràcter ocupacional que té en l'actualitat la funció empresarial, i que es confirma en la informació recollida en els nostres treballadors i treballadores del coneixement. Per aquest motiu, la pregunta pertinent és: «Qui constitueix la demanda d'empresaris i empresàries en les societats tecnològiques avançades?». Doncs bé, el nou paradigma d'organització del teixit empresarial afirma que ha suposat diluir «en gran mesura els estatuts d'ocupació, començant pels professionals, i dissoldre els límits organitzacionals, de tal manera que les identitats d'ocupador, empleat i treballador autèntic s'han vist progressivament substituïdes per meres estructures de gestió de la mà d'obra i per diverses formes de treball precari. L'autèntica pedra filosofal d'aquesta transformació han estat les contínues mutacions empresarials, gràcies a les quals el poder econòmic ha aconseguit fer realitat el somni de la raó governamental liberal, a saber: remercantilitzar la mà d'obra $i$, alhora, convertir les empreses en entitats poc menys que intractables per mitjans legals i governamentals. Ha sorgit, així, tota una gran quantitat d'híbrids, tant en el terreny de l'ocupació com en el de les formes d'organització empresarial» (Frade, 2007: 47).

En realitat, els nostres informants i les nostres informants decideixen ser empresaris i empresàries no davant les expectatives d'un guany esperat, de detectar i captar les oportunitats de beneficis dels mercats, sinó pel maltractament que les organitzacions efectuen a les persones que hi treballen: «Jo ho vaig anar preparant d'alguna manera. Vaig començar a treballar, i va arribar un moment que em vaig quedar amb molt mal sabor de boca, perquè treballava en una empresa privada i allò era tot rebregar i rebregar i rebregar, i no veia cap resultat de res. I aquí cal decidir-se, no treballar per a uns altres i treballar per a mi i ja està. I he anat madurant una mica la idea, no ha estat de cop i volta, l'he anat estudiant, suma aquí o en un altre lloc. I, al final, fer el salt una mica al buit» (GDH5).

Estem davant d'organitzacions que s'assimilen (mitjançant la creació de mercats interns o quasiorganitzacionals) a xarxes de contractes mercantils, amb la qual cosa aconsegueixen dissoldre les seves jerarquies en un medi mercantilitzat poblat per grups d'empreses i cadenes de filials, subcontractades, proveïdors, agències externes, franquícies, aliats i/o socis. A més, s'observa que el comportament dels nostres informants és de fugida o d'evitar el control o la dominació de les seves circumstàncies organitzacionals. Aquests treballadors i treballadores del coneixement han incorporat, d'altra banda, el nou paradigma organitzacional, ja que se'ns informa que «treballen molt amb autònoms, perquè es treballa amb estructures que funcionen per projectes així. Llavors seria més en general, estic pensant $\mathrm{i}$ li he donat moltes voltes i crec que el millor és generar com una xarxa d'autònoms i treballar amb projectes. No tenir unes despeses fixes en la mesura del possible, a part del que seria lloguer de local i tot això. Intentar que 
totes les despeses de recursos humans fossin subjectes a projectes, que estiguin lligades a projectes. Penso que és més còmode per les persones que colllaboren amb un projecte que et passin pressupost $\mathrm{i}$ treballis d'acord amb el pressupost, potser millor que no tinguin un sou, que potser no hi acaba d'estar d'acord, no? Perquè, al principi, no pots pagar grans sous» (EDE7).

Els nostres informants diferencien l'autònom «autèntic» de l'autònom «fals». Així, se'ns diu que «jo soc un autònom autèntic perquè jo sóc el meu propi cap, però la meitat dels autònoms o tres quartes parts dels autònoms estan contractats per empreses, per tant, quan els fan fora no tenen dret a atur». Per això, «són falsos autònoms, perquè se'ls expulsa i no tenen dret a atur, per exemple. I en conec que havien treballat amb institucions oficials. Sí, tenen treballadors amb el règim d'autònoms, treballadors que fitxen vuit hores diàries» (EHE1). Llavors, el problema que pertoca a l'empresarialitat és que cal posar-la en relació amb les pràctiques i les estratègies de reestructuració de les grans corporacions. Processos de reestructuració cap a models flexibles de gestió en xarxa, i que tenen a veure amb el creixement de les Pimes. És el vincle que es dóna entre grans empreses i Pimes, on cal situar el tema de l'empresarialitat i, concretament, les denominades «qualitats de caràcter dinàmic» que caracteritzen l'empresarialitat o l'emprenedoria (innovació, recerca d'oportunitats de negoci, cooperació, risc, ambició, etc.). No cal identificar, llavors, l'empresarialitat amb la creació d'empreses i deixar, així, fora de l'anàlisi el comportament d'empreses ja establertes, les quals constitueixen la motivació extrínseca que origina la decisió de crear una empresa. De fet, els nostres informants són dependents d'alguna empresa privada o d'alguna institució pública. Com ens diu una informant "som uns "pringats", estem supeditats als clients» (EDE7). El client «és el que marca les pautes. Doncs vol això per tal dia, ho vol d'aquesta manera, etc.» (EDE8). Per aquest motiu, es recomana que «el percentatge que té el teu client no sigui un percentatge alt, perquè si aquest client et deixa anar se te'n va el 60 , el 50 o el 30 per cent de la venda que té amb ell. Si no et té agafat, et té atrapat» (GDH5). Ocorre, a més a més, que les nostres persones informants no volien tenir cap superior, però acaben tenint-ne un, el client. Els informants es mouen en l'àmbit del que és laboralment correcte, en el sentit que la seva decisió de tenir una feina autònoma va lligada als nous processos i mètodes de treball i gestió dissenyats amb la finalitat d'economitzar costos de transacció interns i externs a l'empresa. Les estratègies d'economització de costos susciten globalment les mateixes pràctiques laborals i d'organització. Això explica que aquestes persones autònomes es moguin en un terreny definit pel propi teixit empresarial, que, conjuntament amb el context institucional, promociona i legitima l'activitat laboral vinculada a l'autoocupació, al treball autònom, redefinida com una de les formes més viables per accedir al mercat de treball i mantenir-s'hi. Prova d'això és la retòrica managerial sobre el fet que el nombre d'homes i dones ocupadors s'ha incrementat en més del doble en els últims anys. Aquest fet evidencia el dinamisme empresarial. Això no obstant, incorporar-se a l'activitat empresarial, com a treballadors i treballadores autònoms, s'efectua en un marc amb implicacions interessants. 
En primer lloc, les seves raons pràctiques han estat constituïdes a partir d'aquest teixit empresarial. Tota aquesta gent té experiència laboral prèvia, una trajectòria acadèmica i laboral similar, i tota externalitza, i tota està subordinada de diverses maneres a grans empreses client. En teoria, els manca una identitat autònoma més enllà dels encàrrecs assignats per les empreses client, normalment mitjançant contractes mercantils. Així, l'ocupació «es redefineix com un conjunt de tasques, projectes o encàrrecs de treball concrets, mentre que els empleats mateixos es redefineixen com a proveïdors de serveis en relació amb un o més encàrrecs, projectes o campanyes, amb la qual cosa la pertinença a l'organització esdevé irrellevant» (Frade, 2007). En segon lloc, les noves pràctiques de direcció i gestió, en modificar la relació salarial, han generat nous tipus de control: del control tècnic i burocràtic s'ha passat al control cultural i al control pel client, base de l'actual disciplina laboral. D'aquesta manera, s'ha reforçat l'estil de control i la recuperació de la capacitat de governar, en deixar la mà d'obra molt més exposada a mecanismes de mercat i quasimercat. No és casual que, als ulls dels juristes, aquests nous models d'organització permetin els marges de maniobra més grans per gestionar la mà d'obra d'una manera indirecta però summament efectiva. En general, el control i la disciplina es deslliguen de les relacions personals i el manteniment jeràrquic i es reinscriuen «en espais molt més eficaços, com ara l'organització del treball, els llaços d'equip i el mateix jo. Això s'ha assolit, en primer lloc, mitjançant l'establiment de mecanismes de competició i rendició de comptes entre equips de treball indegudament anomenats "autònoms", ja que no hi ha pràcticament agència, només rendiment, i qualsevol autonomia que pogués quedar està enterament subordinada al rendiment. Si alguna cosa es pot dir és que "els treballadors estan més controlats que abans", ja que són els equips mateixos els que tendeixen a actuar com a "policia interna" per controlar els seus membres" (Frade, 2007: 51).

\subsection{Familia i mercat}

En aquest context d'innovació en termes de direcció i gestió, un informant ens diu que «les dones, en aquest món, tenen un estil directiu exageradament masculí» (EHE3). La creença compartida per la totalitat dels nostres informants és que els homes són més egoistes, més agressius, més racionals, mentre que les dones es comporten com a éssers més connectats emocionalment, i per això són més altruistes, solidàries i tenen més empatia. D’aquesta manera, sota la dicotomia egoisme agressiu / emotivitat altruista, homes i dones queden identificats en un pla desigual. Aquesta desigualtat, que és un factor estructurant del món de la producció, explica que, en «un món d'homes» (EDE2, EHE4), hi hagi dones que adoptin la "psicologia masculina» per dirigir les seves empreses. El discurs dels nostres informants és il.lustratiu de com els trets psicològics, és a dir, els estereotips comuns i dominants en la societat en relació amb els homes i les dones i les seves presumptes aptituds laborals es veuen afectats per la pròpia posició estructural. En concret, les característiques psicològiques són alterades 
per l'acompliment de treballs amb determinades característiques, i que les nostres informants consideren que són prèvies, en el sentit que homes i dones posseeixen esquemes de comportament directiu distints. Les característiques atribuïdes a tots dos sexes estan tan incorporades en els esquemes de percepció, acció i apreciació de les nostres informants que, d'una banda, tenim un sector que mostra un rebuig a la formació d'una família, atès que les seves estratègies estan centrades exclusivament en el treball professional. Aquest constitueix un element fonamental en el procés de construcció de la seva identitat, característicament androcèntrica, $\mathrm{i}$ això és degut al fet que la seva atenció prioritària és mantenir-se en el mercat, cosa que les duu a no plantejar-se les relacions de gènere. Justifiquen la seva adscripció exclusiva a l'àmbit del mercat perquè estan fortament influenciades pel gènere masculí. Assumeixen els valors masculins en relació amb el treball i la seva meta és tenir una llar monoparental, unipersonal, «com molts homes» (GDD1).

La realització personal i professional és el motor principal de la manera segons la qual organitzen la seva vida, i el més significatiu és que no mostren cap interès pel feminisme i el gènere. Les seves estratègies personals i professionals estan altament influïdes pel que denominen la "mentalitat masculina». Sobre les formes d'exclusió i discriminació directa i indirecta de les dones, expliquen que són, també, responsabilitat de les dones i consideren que la «bandera feminista les perjudica» (EDE7), que la "discriminació positiva els és negativa» (GDD1), i que no «volen tenir fills ni en tindran, és una opció que altres homes han pres» (GDM2), que «l'important és passar-s'ho bé, gaudir i guanyar diners» (GDM2), és a dir, que tenen clarament assumit el seu rol, és a dir, «un rol molt masculí» (GDD1), i és que, per a aquest segment de dones, el fet de pertànyer al gènere femení no marca característiques determinades en l'estil de direcció, això «va amb la persona. No marca ser dona, sinó la persona» (EDE4). No hi ha distinció «entre homes i dones en la seva professió» (GDD1), i passen «d'aquests rotllos de gènere» (GDM2).

D'aquesta forma, el model masculí interioritzat explica que, en el discurs de les nostres informants, no es reflecteixi el sistema humà de reproducció, en el sentit que el seu temps laboral el distribueixen bàsicament entre treball de mercat i oci, i no entre treball de mercat, treball domèstic i oci. Pel que fa al treball domèstic, totes tenen "una dona que fa la neteja de casa seva» (GDDM2), per tant, respecte al «treball domèstic, cap problema» (GDD1), $i$, respecte al treball mercantil, "has de ser més dura del que ets normalment, un somriure no val i has d'estar sempre de mala bava. Poca simpatia i molt caràcter és el que necessites» (EDE4). Com ens diu una informant, "la dona que és "trepa", és molt "trepa" també, perquè, a més a més, és més llesta" (DDM2), cosa que evidencia que aquestes informants anul-len el seu gènere en el lloc de treball i s'apropien del gènere dominant, que l'utilitzen per afermar i consolidar la seva trajectòria, les seves expectatives d'èxit professional i de vida independent. D'aquesta manera, marquen el lloc de treball com a pertanyent al gènere masculí i reprodueixen en la seva pràctica laboral les estructures patriarcals del treball productiu. 
D'altra banda, en un altre sector de les nostres informants, s'hi constata que assumeixen un model de maternitat caracteritzada per una intensa proximitat afectiva i una implicació activa en la cura i l'atenció de les seves criatures, i, també, al marit. Són dones que han optat pel treball autònom perquè els permet, a diferència de la feina assalariada, tenir una família i responsabilitats a la llar. Prioritzen la família per damunt dels seus projectes professionals, en el sentit que atribueixen a la formació d'una família una rellevància tan gran que continua ocupant un lloc privilegiat en les seves aspiracions i expectatives, al mateix temps que no es plantegen transformar els models de funcionament de la vida en parella, això és, no pensen efectuar un reajustament dels rols domèstics, ja que, tal com està organitzada la família nuclear, els proporciona un sentiment de més seguretat i superioritat. Això ho justifiquen per la percepció que tenen sobre si mateixes i sobre la problemàtica de la maternitat, la qual les distingeix dels homes. És a dir, el que les distingeix és «la possibilitat de tenir un fill [...]. La possibilitat de donar de mamar. Doncs això ells no ho tenen [...]. Però a veure per a mi. Això de la dona, a veure què volem..., igualar-nos a l'home..., i tots aquests rotllos? A mi no m'interessa igualar-m'hi en cap sentit, perquè jo no em vull igualar a una pauta social de treballar com un imbècil tot el dia sense veure la meva família. Què busco com a dona? Això. Ni parlar-ne, si sabem que ha fracassat. Si jo he vist que ja va fracassar en l'home, com he de voler el mateix com a dona? Això no m’interessa, ni regalat. El que vull és un altre sistema. Un sistema..., el que sigui..., però aquest no. Jo no vull ser directiva agressiva, estressada, amb 700 mòbils, que no vegi mai els meus fills» (EDE8).

La importància que atribueixen a la família posa de manifest que, per a elles, l'èxit professional, el que denominen «la felicitat», és tenir una família, encara que sigui monoparental. Famílies que defineixen com un àmbit afectiu i emocional, un àmbit de benestar sentimental que no troben en el treball productiu. La informació recollida mostra que, en aquestes famílies «afectives i emocionals», s'ha millorat en la renda familiar pel doble ingrés, però poc s'ha avançat cap a unes relacions més simètriques, cap a la consecució d'una igualtat efectiva. El més significatiu és que, per a elles, ni hi ha crisi ni cal transformar la lògica interna de les relacions familiars, encara que sigui «molt complicat compaginar la meva vida amb nens. Els meus horaris són intempestius, surto de casa a les vuit del matí i no hi arribo fins a les onze de la nit [...]. La majoria dels dies dino i sopo fora de casa, així que a casa meva només hi dormo. És com si estigués en un hotel. El meu company gairebé ni em veu. Ja hem comentat alguna vegada que l'única solució per tenir fills és que hi hagi una persona interna a casa que es faci càrrec de les tasques domèstiques i del bebè. Que cuini menjars i sopars, prepari rentadores, planxi roba, etc. De fet, ja tenim una senyora que ens ajuda amb la casa, hi ve els divendres durant cinc hores. Fa el més gran i sobretot planxa i prepara rentadores. En un primer moment, em vaig decidir fer-me autònoma perquè creia que podria permetre'm tenir fills sense pressions i quan jo ho decidís. Compliré els trenta-dos i ja és una edat en la qual em plantejo tenir família. I suposo que el meu treball és problemàtic per atendre les necessitats mínimes dels nens, però crec que ho puc compaginar» 
(EDE4), ja que «la dona cerca, o jo busco aquella feina que tingui una flexibilitat per poder compaginar família i feina i l'home» (EDE10).

Aquest sistema "família i feina i l'home» es manté, també, pel rol dels avis i les àvies cuidadors. Aquestes figures estan molt presents en la dinàmica familiar de les nostres informants. Una dinàmica que tot el que no és «afectiu», «emocional» se subcontracta. La filosofia és que la llar és un refugi emocional, altament funcional per al manteniment de la funció reproductiva en el sistema capitalista. Un refugi basat en l'amor de la dona als fills i al marit, i que fa cas omís del predicament feminista o, més aviat, per a elles la manipulació es porta a terme per les feministes. Una llar en la qual el comportament del marit es percep com una mica «natural», «biològic», específic dels «homes», «ells són com són» (GDD1, GDM2).

Es contempla, llavors, amb naturalitat, la funció tradicional reproductiva i no s'observa en les nostres informants cap mena de lluita per la igualtat de gènere, ni en el treball productiu ni en el treball domèstic. Són dones de classe mitjana que ocupen una posició de privilegi laboral (no exerceixen feines per sota de la seva categoria professional, sinó que aquestes estan d'acord amb la seva preparació acadèmica i tenen ocupacions amb prestigi social) i assolida pel doble ingrés, i les seves responsabilitats i lleialtats familiars són molt presents en el seu accés al treball autònom en condicions molt favorables per a les «empreses client». Dones que resolen la feina domèstica no emocional ni afectiva amb força de treball immigrada en condicions econòmiques molt favorables per a elles. Tots aquests aspectes expliquen que les nostres informants "passin d'aquests rotllos de gènere», és a dir, de les desigualtats existents entre homes i dones. Aquesta situació, viscuda per les nostres informants com familiarment i laboralment "correcta», explica que els nostres informants respecte al repartiment del treball domèstic ens diguin que les dones han «agafat el rol i se senten còmodes així» (EHI2).

\section{Conclusions}

En el feminisme, hi ha la convicció que, com qualsevol procés social, la lluita per la igualtat de gènere serà llarga $i$, desgraciadament, costosa. La informació recollida avala aquesta convicció, però apunta que, en el manteniment de la dominació masculina, hi ha un consentiment de les pròpies «víctimes». D'una banda, aquest consentiment s'observa en un sector de les nostres informants que assumeixen la compatibilitat total entre família i mercat (i les seves condicions correlatives d'ocupació i treball), i això per la importància que la família té en els seus projectes empresarials i/o professionals, i que les duu a entremesclar constantment la feina productiva i la reproductiva. L'estrès (o els costos) que la doble activitat els genera es racionalitza en termes de la lògica del benefici emocional, de guanys afectius i sentimentals que associen a la vida familiar. Vida familiar que té clars biaixos classistes, pel fet que la vida emocional d'aquestes famílies està relacionada amb la transferència, el transvasament, la subcontractació d'activitats domèstiques a unes altres dones. Aquesta subcontractació 
permet que la família tingui aquest aire d'inclinació «afectiva i emocional» que és absent en el treball productiu, tal com se'ns informa en el grup de discussió de tècniques i responsables de serveis de suport a la persona emprenedora.

D'altra banda, el consentiment s'observa, també, en l'altre sector de les nostres informants, en el qual crear una família no forma part dels seus projectes individuals d'èxit professional. Dones que són al mercat i que s'hi mantenen, $i$ això no és tan degut al seu gènere socialment assignat, com al gènere que imiten. Dones que no mostren cap sensibilitat per les diferències de gènere ni experimenten conflicte de lògiques (productiva i reproductiva). La seva acceptació social de dones «autònomes», "professionals», implica el rebuig del rol de mares i esposes. Per a elles, el prioritari és complir al «màxim» en el mercat, en el treball productiu. Si en les informants anteriors la doble presència ha suposat un canvi en el model de gènere, en el sentit de passar de ser "mestressa» a ser "una superdona», en aquestes últimes el canvi és deixar de ser «mestresses» per ser «un superhome». Tots dos tipus de dones estan en una posició social des de la qual no es qüestiona el conjunt del món on viuen (un món de divisions i jerarquies socials) i en el qual construeixen les seves estratègies de reproducció social.

D'altra banda, en el cas de les dones empresàries, la seva estructura de capital està ordenada, en primer lloc, pel seu capital cultural i social, i els utilitzen tots dos per convertir-lo en capital econòmic. Les seves oportunitats ocupacionals depenen de la trajectòria escolar (ocupació per compte aliè) i laboral (ocupació per compte propi). En conjunt, les trajectòries i les motivacions dels homes són similars a les de les dones. Així mateix, l'anàlisi de les experiències empresarials ha mostrat que els empresaris i les empresàries són un empresariat «micro». La seva situació és dictada per l'organització actual de la producció, la qual és omnipresent en els discursos dels nostres informants. Políticament (re) presentats i (re)presentades com a reflex del denominat «esperit empresarial», els nostres empresaris i empresàries són subjectes actius, permanentment mobilitzats, disponibles i preparats per treballar per compte propi, considerat com un estat «natural», millor que el «vulgar» treball assalariat. Subjectes l'ocupació dels quals s'ha generat per l'aplicació de tècniques de gestió com ara dowsizing, externalització, networking, filiació, franquícies i altres formes de desagregació vertical i cooperació horitzontal.

La manca de legitimitat del feminisme per a les nostres informants s'explica perquè la seva subjectivitat ha estat socialitzada en els «ideals d'èxit» masculí. Una subjectivitat que ha assimilat els estereotips masculins en relació amb l'activitat productiva i reproductiva, i que és el producte d'una configuració espaciotemporal particular dels espais de vida. La valoració de les pràctiques $\mathrm{i}$ del seu rol com a mares (i la irrellevància que atorguen a la resta de les tasques domèstiques que tradicionalment executaven les «mestresses») d'un sector de les nostres informants, i el rebuig i la desvalorització que pateix per part d'altres informants, concretament el rebuig que mostren a viure la «maternitat», concebuda com un obstacle per a les seves oportunitats de mercat, constitueixen preses de posició, simètriques, de dones heterosexuals, occidentals, blanques i econòmicament privilegiades. 


\section{Bibliografia}

Acs, Z.; Arenius, P.; Hay, M. i Minniti, M. (2005). Global Entrepreneurship Monitor. Executive Report 2004. Babson Park: Babson College and London Business School.

Audretsch, D.B. i Thurik, R. (2002). Linking Entrepreneurship Growth. OECD STI Working Paper, 2081/2.

Bodey, R.J. Jr. (1999). «Flexible Working Hours, Family Responsibilities». American Journal of Economics \& Sociology, 58 (1), 71-83.

Bradley, H. (1999). Gender and power in the workplace. Houndmills: Macmillan.

Brunet, I. i Alarcón, A. (2005). ¿Quién crea empresas?: Redes y empresarialidad. Madrid: Talasa.

CÁnoves, G. (1994). «Estructura familiar i treball de la dona a l'agricultura: El cas d'Osona i el Baix Empordà». Documents d'Anàlisi Geogràfica, 26, 53-71.

Cánoves, G. i Garcia Ramon, M.D. (1995). «El turismo rural, alternativa o complemento de la agricultura: Las mujeres motores de la transformación». El Campo, $133,221-238$.

Cánoves, G.; Villarino, M. (2000a). «Turismo rural en Portugal: Las mujeres, piezas clave para "recibir y servir"». A: Garcia Ramon, M.D.; Baylina, M. (eds.) (2000). El nuevo papel de las mujeres en el desarrollo rural. Vilassar de Mar: Oikos-Tau.

- (2000b). "Turismo en espacio rural en España: actrices e imaginario colectivo». Documents d'Anàlisi Geogràfica, 37, 51-77.

Caputo, R.K. i Dolinsky, A. (1998). «Women's Choice to Pursue Self-Employment: The Role of Financial and Human Capital of Household Members». Journal of Small Business Management, juliol, 8-17.

Carter, N. i Williams, M. (2003). "Comparing social feminism and liberal feminism». A: Butler, J. (ed.). New perspectives on women entrepreneurs. Greenwich, CT: IAP.

Carter, S. (2000). "Gender and enterprise». A: Carter, S. i Jones-Evans, D. (eds.). Enterprise and small business: Principles, practice and policy. Londres: Prentice Hall.

Chinchilla, N. i León, C. (2003). Les millors pràctiques de conciliació treball-familia a l'empresa. Barcelona: Generalitat de Catalunya.

- (2004). Cómo reconciliar trabajo y familia: La ambición femenina. Madrid: Aguilar.

Comisión de las Comunidades Europeas (2003). Libro verde. El espiritu empresarial en Europa. Brussel.les: COM.

Connely, R. (1992). "Self-employment and Providing Child Care». Demography, $29(1), 17-29$.

Cuervo, A. (2005). «Individual and Environmental Determinants of Enterpreneurship». International Enterpreneurship and Management Journal, vol. 1 (1), 293-311.

Devi, U. (2000). Care and Freedom. Center for Working Families. Berkeley: University of California. [www.bc.edu/bc_org/avp/wfnetwork/berkeley/papers/op1.pdf]

DíAz, C. (2002). La creación de empresas: Revisión histórica de teorías y escuelas. Trujillo: La Coria.

Fisher, E.; Reuber, R. i Dyke, L. (1993). «A theoretical overview and extension of research on sex, gender and entrepreneurship». Journal of Business Venturing, 8 (4), 151-168.

Frade, C. (2007). «Gobernar a otros y gobernarse a sí mismo según la razón política liberal». Revista Española de Investigaciones Sociológicas (REIS), 119, 35-63.

Gallo, M.A. (1997). La empresa familiar. Barcelona: Biblioteca IESE de Gestión de Empresas. 
Garcia Ramon, M.D.; Baylina, M. (2000). El nuevo papel de las mujeres en el desarrollo rural. Vilassar de Mar: Oikos-Tau.

Greer, M. i Green, P. (2003). "Feminist theory and the study of entrepreneurship». A: Butler, J. (ed.). New perspectives on women entrepreneurs. Greenwich, CT: IAP.

Guallarte, C.; Obis, T.; Rialp, A.; Surís, J.M. i Tarragó, A. (2006). Global Entrepreneurship Monitor: Informe ejecutivo Cataluña 2005. Barcelona: Institut d'Estudis Regionals i Metropolitans de Barcelona, Universitat Autònoma de Barcelona, Generalitat de Catalunya-Departament de Treball i Indústria, Diputació de Barcelona.

Guallarte, C. (dir.) (2009). Global Entrepreneurship Monitor: Informe executiu Catalunya 2008. Barcelona: Institut d'Estudis Regionals i Metropolitans de Barcelona, Universitat Autònoma de Barcelona, Generalitat de Catalunya-Departament de Treball i Indústria, Diputació de Barcelona.

Guzmán, J. i Romero, I. (2006). «La política europea de fomento empresarial». A: Galindo, M.A. i Fernández, Y. (coords.). Política socioeconómica en la Unión Europea. Madrid: Delta.

Kantor, P. (2002). "Gender, microenterprise success and cultural context: The case of South Asia». Entrepreneurship Theory and Practice, 26 (3), 131-143.

Lundström, A. i Stevenson, L. (2001). «Entrepreneurship Policy for the Future». Volum 1 d'Entrepreneurship Policy for the Future Series. SME Forum, Växjö, març. Estocolm: Swedish Foundation for Small Business Research.

- (2002). "On the Road to Entrepreneurship Policy». Volume 1 d'Entrepreneurship Policy for the Future Series. Estocolm: Swedish Foundation for Small Business Research.

Marlow, S. (2002). «Self employed women: Apart of, or apart from, feminist theory?». Entrepreneurship and Innovation, 2 (2), 83-91.

MerCADÉ, A. (1998). Mujer emprendedora: claves para crear y dirigir empresas excelentes. Barcelona: Gestión 2000.

OCDE (2001). Entrepreneurship, Growth and Policy. París: OCDE.

Oso, L. i Ribas, N. (2004). "Empresariado étnico y género: Dominicanas y marroquíes a Madrid y Barcelona». 40 Congreso sobre la inmigración en España, 10-13 de novembre, Girona.

Pérez Orozco, A. (2007). Perspectivas feministas en torno a la economía: El caso de los cuidados. Madrid: Consejo Económico y Social.

Pérez, J.A. i Chinchilla, M.N. (1995). La mujer y su éxito. Pamplona: Eunsa.

SACRISTÁn, M. (2002). «La dirección estratégica de empresas familiares como proyecto de investigación». Boletín de Estudios Económicos, 57 (177), 517-542.

SÁrz, A. (2003). "Mujeres inmigradas empresarias: El caso de las chinas». II Congreso de Inmigración Africana. Las mujeres inmigradas en España, 24, 25 i 26 d'abril de 2003, Almeria.

SAmpedro, R. (1996). Género y ruralidad: Las mujeres ante el reto de la desagrarización. Madrid: Instituto de la Mujer.

Segarra, A. (dir.) (2002). La creación y la supervivencia de las empresas industriales. Madrid: Civitas. Colección Economía.

Shaw, E.; CARTER, S. i Brierton, J. (2001). Unequal entrepreneurs: Why female enterprise is an uphill business. Londres: The Industrial Society.

Solé, C. i Parella, S. (2005). Negocios étnicos: Los comercios de los inmigrantes no comunitarios en Catalunya. Barcelona: Fundació CIDOB. 
Urbano, D. i Veciana, J.M. (2001). «Marco institucional formal de la creación de empresas en Cataluña». XI Congreso Nacional de ACEDE.

Urbano, D. (2006). La creación de empresas en Catalunya: Organismos de apoyo y actitudes hacia la creación de empresas. Barcelona: Generalitat de Catalunya. Colección de estudios CIDEM.

Veciana, J.M. (1985). «Empresario y procesos de creación de empresas». Revista Econòmica de Catalunya, 8, 15-29.

- (1988). «Empresari i procés de creació d'empreses». Revista Econòmica de Catalunya, 8 (maig-agost), 53-67.

- (1999). "Creación de empresas como programa de investigación científica». Revista Europea de Dirección y Economía de la Empresa, 8 (3), 11-36.

- (2005). La creació d'empreses: Un enfocament gerencial. Barcelona: «La Caixa».

Williams, F. (2004). Rethinking Families. Londres: Calouste Gulbenkian Foundation. 